\title{
Uso dos resíduos de maracujá como adsorvente alternativo para a adsorção de
}

\section{corante}

\author{
Use of passion fruit waste as an alternative adsorbent for dye adsorption
}

Uso de residuos de maracuyá como adsorbente alternativo para la adsorción de colorante

\section{Resumo}

O presente trabalho teve como objetivo avaliar os resíduos de maracujá (cascas e sementes), como adsorventes alternativos para o tratamento de efluentes contaminados por corante Vermelho Quimicryl GRL, testar o efeito da força iônica e do $\mathrm{pH}$ na eficiência no processo de adsorção e por fim verificar se o processo de dessorção é viável. O processo de adsorção foi conduzido em coluna de leito fixo com o adsorvente in natura e tratado com $\mathrm{NaOH}$ (hidróxido de sódio). Foi avaliado o efeito da força iônica utilizando junto a solução do corante $\mathrm{NaCl}$ (cloreto de sódio) em diferentes concentrações, os pHs avaliados foram 2, 5, 7 e 12, o processo de dessorção foi avaliado utilizando como solução extratora $\mathrm{HCl}$ (ácido clorídrico). Com isso observou-se que a adsorção foi favorecida pela biomassa tratada com $\mathrm{NaOH}$, o efeito da força iônica apresentou influência sobre o processo de adsorção, sendo que para a amostra com concentração de $\mathrm{NaCl}$ de $1,0 \mathrm{~mol} \mathrm{~L}^{-1}$ o processo de adsorção foi vantajosa, o $\mathrm{pH}$ influenciou de forma direta no processo, sendo que quanto maior o valor de $\mathrm{pH}$ a afinidade de adsorção aumenta, logo o melhor $\mathrm{pH}$ testado foi o de 12. A melhor biomassa testada foram as cascas de maracujá tratadas com $\mathrm{NaOH}$ com valor de capacidade máxima de adsorção de $45,9 \mathrm{mg} \mathrm{g}^{-1}$ para o corante analisado.

Palavras-chave: Adsorção; Coluna de Leito Fixo; Cascas de Maracujá; Corantes.

\begin{abstract}
The present work aimed to evaluate the passion fruit residues (shells and seeds) as alternative adsorbents for the treatment of effluents contaminated by Red Quimicryl GRL dye, test the effect of ionic strength and $\mathrm{pH}$ on the efficiency of the adsorption process and finally check whether the desorption process is feasible. The adsorption process was carried out in a fixed bed column with the adsorbent in natura and treated with $\mathrm{NaOH}$ (sodium hydroxide). The effect of ionic strength was evaluated using together the dye solution $\mathrm{NaCl}$ (sodium chloride) at different concentrations, the pHs evaluated were 2, 5, 7 and 12, the desorption process was evaluated using $\mathrm{HCl}$ (hydrochloric acid) as an extracting solution. Thus, it was observed that the adsorption was favored by the biomass treated with $\mathrm{NaOH}$, the effect of ionic strength influenced the adsorption process, and for the sample with $1.0 \mathrm{~mol} \mathrm{\textrm {L } ^ { - 1 }}$ $\mathrm{NaCl}$ concentration, the adsorption process was advantageous, the $\mathrm{pH}$ directly influenced the process, and the higher the $\mathrm{pH}$ value the adsorption affinity increases, so the best $\mathrm{pH}$ tested was 12 . The best biomass tested were passion fruit husks treated with $\mathrm{NaOH}$ with value of maximum adsorption capacity of $45.9 \mathrm{mg} \mathrm{g}^{-1}$ for the analyzed dye.
\end{abstract}

Keywords: Adsorption; Fixed Bed Column; Passion fruit husks; Dyes.

\section{Resumen}

El presente trabajo tuvo como objetivo evaluar los residuos de maracuyá (cáscaras y semillas) como adsorbentes alternativos para el tratamiento de efluentes contaminados por colorante Red Quimicryl GRL, probar el efecto de la fuerza iónica y el pH sobre la eficiencia del proceso de adsorción y finalmente verificar si el proceso de desorción es 
factible. El proceso de adsorción se realizó en columna de lecho fijo con el adsorbente in natura y se trató con $\mathrm{NaOH}$ (hidróxido de sodio). El efecto de la fuerza iónica se evaluó utilizando en conjunto la solución de colorante $\mathrm{NaCl}$ (cloruro de sodio) a diferentes concentraciones, los pH evaluados fueron 2, 5, 7 y 12, el proceso de desorción se evaluó utilizando $\mathrm{HCl}$ (ácido clorhídrico) como solución extractora. Así, se observó que la adsorción fue favorecida por la biomasa tratada con $\mathrm{NaOH}$, el efecto de la fuerza iónica influyó en el proceso de adsorción, y para la muestra con una concentración de $\mathrm{NaCl} 1.0 \mathrm{~mol} \mathrm{~L}^{-1}$, el proceso de adsorción fue ventajoso, el $\mathrm{pH}$ influyó directamente el proceso, y cuanto mayor es el valor de $\mathrm{pH}$ aumenta la afinidad de adsorción, por lo que el mejor pH probado fue 12 . La mejor biomasa probada fueron las cáscaras de maracuyá tratadas con $\mathrm{NaOH}$ con un valor de capacidad máxima de adsorción de 45,9 $\mathrm{mg} \mathrm{g}^{-1}$ para el colorante analizado.

Palabras clave: Adsorción; Columna de lecho fijo; Cáscaras de maracuyá; Tintes.

\section{Introdução}

Existem diferentes classes de corantes usados para o tingimento têxtil, os corantes ácidos, quais são geralmente utilizados no tingimento de seda, lã, acrílicos modificados, náilon e de couro. As principais classes de corantes ácidos são azina, xanteno, antraquinona, trifenilmetano, nitroso, nitro, azo, Azul ácido 2, vermelho ácido 57, laranja de metila e laranja (I, II) (Salleh, Mahmoud, Karim, \& Idris, 2011). Os corantes básicos são usados para poliésteres modificados, nylons modificados, tingimento de poliacrilonitrila, bem como na indústria de papel, algodão mordente de tanino, seda e lã (Salleh, Mahmoud, Karim, \& Idris, 2011). Esta classe de corantes é solúvel em água e produz cátions coloridos e também são chamados de corantes catiônicos. Suas principais classes são cianina, tiazina, acridina, oxazina, hemicianina e diazahemicianina, ou seja, vermelho básico 46, verde malaquita, amarelo básico 28, violeta cristal, azul de metileno, o castanho básico e o vermelho básico 9 (Bouatay, Dridi-Dhaouadi, Drira, \& Farouk Mhenni, 2016).

O polo da confecção é uma das indústrias brasileiras que mais utilizam corantes, sendo que desse total cerca de $20 \%$ é descartado, esse descarte gera efluentes altamente coloridos por conta de corantes que não se fixaram completamente na fibra, esses efluente vem causando grandes problemas ambientais e vem chamando atenção de vários setores da sociedade, com isso tratar esses descarte se faz necessário (Guaratini \& Zanoni, 2000; Dallago, Smaniotto, \& Oliveira, 2005; Pinto et al., 2016; Bharathi \& Ramesh, 2013). Essa estratégia de tratamento garantirá uma solução otimizada para proteger as fontes de água subterrânea, terras agrícolas e vida aquática (Aleem et al., 2020).

A adsorção é um dos processos de separação industrial mais importantes para o tratamento de efluentes, além da técnica apresentar-se alto potencial para o tratamento de efluentes, devido a sua grande capacidade de purificação de águas contaminadas e aspectos econômicos (como baixo custo e acessibilidade) (Peker, Yapar, \& Besün, 1995; Ncibi, Mahjoub, \& Seffen, 2007). Na pesquisa de Assila et al. (2020) houveram resultados positivos em tratamentos sob pH 10, possivelmente devido à formação de ligações de hidrogênio na superfície entre os grupos hidroxila em ambas as superfícies dos adsorventes e os grupos funcionais dos corantes têxteis.

Adsorção trata-se de um processo de transferência de massa do qual o adsorvente (geralmente uma substância sólida) pode remover seletivamente os constituintes dissolvidos de uma solução aquosa, atraindo o soluto dissolvido para sua superfície; o adsorvente pode existir na fase líquida, sólida, gasosa ou soluto dissolvido (Kausar et al., 2018). Embora no ramo de tratamento de efluentes, os tratamentos químicos produzam mau cheiro e subprodutos; fenômenos de adsorção são de interesse para remoção de corantes devido ao seu baixo custo e flexibilidade no design, por esse processo não produzir nenhuma substância após a remoção dos compostos alvo. É por isso que esse processo é amplamente usado para a remoção de tintas e pigmentos (Rahmani \& Sasani, 2016; Acharya, Kumar, \& Rafi, 2018).

Adsorção física é um processo no qual, a interação adsorvente adsorvato se dá por meio de interações intermoleculares, sendo possível regenerar o ambos adsorvente e adsorvato após o processo de adsorção, esta seguirá as ligações de hidrogênio, polaridade, forças de Vander Waals e interações dipolo-dipolo, etc. Além disso, pode existir a adsorção 
química, se caracteriza por meio de ligações químicas devido a troca de elétrons, o adsorvato é quimicamente ligado a superfície, não sendo possível regeneração ao final do processo (Abd, Naji, Hashim, \& Othman (2020).

A adsorção possui alta capacidade de adsorção para todos os tipos de corantes; troca iônica, qual não ocorre perda de sorvente; coagulação eletrocinética, técnica economicamente viável; e a filtração por membrana, técnica eficaz para todos os tipos de efluentes e corantes com alta qualidade (Kausar et al., 2018).

Para avaliar o comportamento termodinâmico de adsorção, os valores da energia livre de Gibbs mudam $\left(\Delta G^{0}, \mathrm{~kJ}\right.$ $\left.\mathrm{mol}^{-1}\right)$, ocorre mudança de entalpia $\left(\Delta \mathrm{H}^{0}, \mathrm{~kJ} \mathrm{~mol}^{-1}\right)$ e mudança de entropia $\left(\Delta S^{0}, \mathrm{~kJ} \mathrm{~mol}^{-1} \mathrm{~K}^{-1}\right)$ da mesma forma que relatado na literatura (Ruthven, 1984; Milonjić, 2007). A adsorção de íons metálicos em um determinado adsorvente torna-se um processo mais interessante se for possível recuperar os íons adsorvidos ao final do tratamento e, embora a maioria dos biossorventes correspondam a materiais abundantes de baixo custo, a possibilidade de reaproveitamento desses materiais depois que a recuperação de íons é atraente (Gerola et al., 2013).

Existem diversos efeitos de vários fatores críticos, como concentração inicial do corante, $\mathrm{pH}$ da solução, temperatura e dose do adsorvente no desempenho de adsorção do corante. Vários adsorventes, como materiais à base de carbono, óxidos de metal, bio-adsorventes e materiais à base de polímeros, têm se mostrado eficientes para a remoção de poluentes corantes de águas residuais. Esses adsorventes possuem as vantagens de fácil fabricação, alta área de superfície efetiva, multifuncionalidades, alta proporção de volume de superfície, alta reatividade, grande número de sítios ativos, reutilização, baixo custo e alta eficiência para tratar compostos recalcitrantes (Dutta, Gupta, Srivastava, \& Gupta, 2021).

A indústria alimentícia produz resíduos que podem ser utilizados como adsorventes alternativos para tratamento de efluente têxtil, um exemplo é a indústria que utiliza maracujá, o Brasil apresenta destaque mundial em sua produção, seja da polpa ou do suco, sendo que durante o processamento do maracujá são obtidos dois subprodutos da extração da polpa ou do suco, os resíduos são as cascas e sementes, que na grande maioria das vezes não tem um reaproveitamento adequado (Samico, 2010; Khuwijitjaru \& Klinchongkon, 2020).

Diante do exposto o objetivo do presente trabalho é de avaliar os resíduos de maracujá, nesse casso as cascas e sementes de maracujá, como adsorvente alternativo para o tratamento de efluente com o corante vermelho Quimacryl - GRL, testar o efeito da força iônica e do pH na eficiência no processo de adsorção e por fim verificar se o processo de dessorção pode acontecer.

\section{Metodologia}

\subsection{Amostra}

O design selecionado para o presente estudo foi laboratorial e cientifico (Pereira, Shitsuka, Parreira, \& Shitsuka, 2018). Preparou-se soluções estoques de $1 \mathrm{~g} \mathrm{~L}^{-1}$ do corante vermelho Quimacryl - GRL. Para a determinação do comprimento de onda máxima de absorção, obtiveram-se espectros de absorção na região do visível. Para a obtenção dos espectros utilizouse cubetas de poliestireno com $1 \mathrm{~cm}$ de caminho óptico e espectrofotômetro UV-VIS da Perkin Elmer, e realizou-se uma varredura entre 400 e $720 \mathrm{~nm}$, encontrando-se dessa forma os valores de $\lambda_{\operatorname{máx}}$ para o corante.

\subsection{Obtenção dos resíduos de Maracujá}

As frutas de maracujá (Passiflora edulis) foram obtidas em frutarias da cidade de Apucarana - PR. Inicialmente separou-se a polpa das cascas, em seguida as cascas foram trituradas utilizando um liquidificador e foi reservado a amostra. O processo repetiu-se para a polpa, separando-as das sementes após trituração. 
Posteriormente lavaram-se as cascas e sementes, de forma individual em água corrente, em seguida os mesmos foram secos em estufa com circulação de ar à $80^{\circ} \mathrm{C}$ por 12 horas. Logo após os resíduos foram triturados novamente e peneirados em peneira de $425 \mu \mathrm{m}$, para assim obter uma granulometria mais uniforme. Dessa forma obtivemos dois resíduos, as sementes e as cascas.

\subsection{Tratamentos dos resíduos de maracujá}

Os resíduos de maracujá passaram por um tratamento químico, de forma isolada, casca das sementes. Realizou-se o tratamentos químico com hidróxido de sódio $(\mathrm{NaOH})$ na concentração de $0,10 \mathrm{~mol} \mathrm{~L}^{-1}$. Para a execução desse tratamento, em béqueres de $250 \mathrm{~mL}$ misturou-se $20 \mathrm{~g}$ de cascas de maracujá com $150 \mathrm{~mL}$ das soluções básicas. Agitaram-se as misturas por 1 hora à temperatura ambiente em agitador magnético. Em seguida os resíduos foram lavados com água destilada e secados em estufa com circulação de ar à $80{ }^{\circ} \mathrm{C}$ durante 6 horas. Após isso realizou-se o mesmo tratamento para as sementes, da mesma maneira como descrita acima.

Dessa forma, os estudos de adsorção foram realizados com os resíduos (cascas e sementes) in natura, tratado com $\mathrm{NaOH}$.

\subsection{Estudos de adsorção}

Os ensaios de adsorção foram realizados coluna de leito fixo assim como proposto por Montanher, de Farias, \& Dalpasquale (2019).

\subsubsection{Efeito da força iônica}

Para esse estudo preparou-se solução do corante vermelho Quimicryl GRL usando como eletrólito o cloreto de sódio $(\mathrm{NaCl})$ em duas concentrações: 0,10 e $1,0 \mathrm{~mol} \mathrm{~L}^{-1}$. Em seguida os estudos de adsorção foram conduzidos como descrito anteriormente.

\subsubsection{Efeito do $\mathrm{pH}$}

Para esse estudo a solução do corante vermelho Quimicryl GRL foi preparada em pH 2, pH 12 (ajustados com HCl ou $\mathrm{NaOH} 0,10 \mathrm{~mol} \mathrm{~L}^{-1}$ ) e no pH natural da solução aquosa do corante. Em seguida os estudos de adsorção foram conduzidos como descrito anteriormente.

\subsubsection{Obtenção das curvas de saturação e dessorção}

Para a obtenção das curvas de saturação percolou-se as soluções do corante vermelho Quimicryl GRL até a total saturação do adsorvente. Curvas de volume percolado $(\mathrm{mL})$ por $\mathrm{C}_{\mathrm{v}} / \mathrm{C}_{\mathrm{i}}$ foram traçadas. Onde $\mathrm{C}_{\mathrm{v}}$ é a concentração do corante na alíquota percolada e $\mathrm{C}_{\mathrm{i}}$ concentração inicial do corante $\left(50 \mathrm{mg} \mathrm{L}^{-1}\right)$. Após a saturação, que foi constatada quando a coloração de entrada na coluna era igual a coloração de saída, as colunas foram percoladas com solução de $\mathrm{NaOH} 0,10 \mathrm{~mol} \mathrm{~L}^{-1}$ para a dessorção do corante. Recolheu-se alíquotas de $25 \mathrm{~mL}$ do corante. As curvas de dessorção foram obtidas plotando-se o volume percolado da solução extratora pela concentração de corante extraído $\left(\mathrm{mg} \mathrm{L}^{-1}\right)$. 


\subsubsection{Cálculo da capacidade máxima de adsorção}

A capacidade máxima de adsorção do adsorvente presente em uma coluna, q ( $\left.\mathrm{mg} \mathrm{g}^{-1}\right)$, expressa a quantidade de adsorvato que pode ser adsorvido por grama de adsorvente e pode ser determinada pela Equação 1 (Geankopolis, 1993).

$$
q=\frac{C_{i} \cdot Q}{m} \int_{0}^{t}\left(1-\frac{C v}{C i}\right) d t
$$

Onde:

$\mathrm{q}$ = capacidade máxima de adsorção $\left(\mathrm{mg} \mathrm{g}^{-1}\right)$;

$\mathrm{C}_{\mathrm{i}}=$ concentração inicial do adsorvato $\left(\mathrm{mg} \mathrm{L}^{-1}\right)$;

$\mathrm{C}_{\mathrm{v}}=$ concentração do fluido na saída da coluna $\left(\mathrm{mg} \mathrm{L}^{-1}\right)$;

$\mathrm{Q}=$ vazão volumétrica da solução $\left(\mathrm{L} \mathrm{min}^{-1}\right)$;

$\mathrm{t}=$ tempo $(\min )$

$\mathrm{m}=$ massa seca do adsorvente $(\mathrm{g})$.

Para a determinação de "q" utilizou-se o software Origin 8.0. Um gráfico de tempo $(\min )$ versus $\left(1-\mathrm{C}_{\mathrm{v}} / \mathrm{C}_{\mathrm{i}}\right)$ foi plotado e a área sobre o gráfico determinada. Essa área foi então multiplicada pelo fator $\mathrm{C}_{\mathrm{i}} \cdot \mathrm{Q} / \mathrm{m}$.

\section{Resultados e Discussão}

Para que a quantificação do corante vermelho Quimacryl GRL fosse possível de ser determinada, primeiramente os valores de $\lambda_{\text {máx }}$ para o corante teve que ser encontrado, para isso realizou-se uma varredura entre 400 e $720 \mathrm{~nm}$ para encontrar o seguinte espectros de absorção na região do visível (Figura 1).

Figura 1. Espectros de Absorção na região do visível para os vermelho Quimacryl GRL.

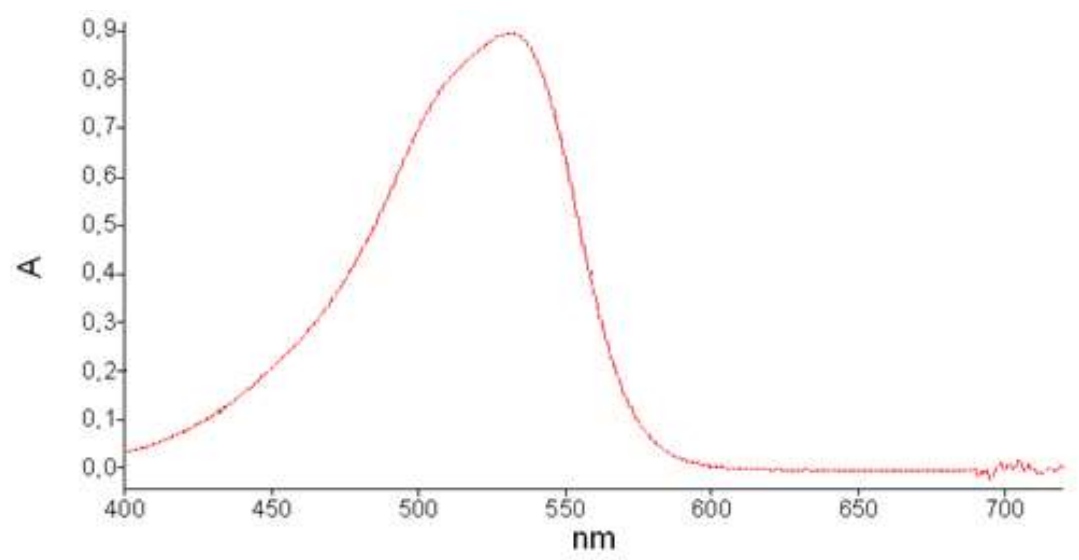

Fonte: Autores (2021).

Utilizando o espectro de absorção foi possível encontrar o valor de $\lambda_{\operatorname{máx}}$ que para o corante vermelho Quimacryl GRL é de $530 \mathrm{~nm}$. 
Com os valores de $\lambda_{\text {máx }}$ foi possível construir uma curva de calibração para o corante vermelho, essa curva foi utilizada para determinação da concentração de corante que era recolhido após passagem pela coluna. A curva de concentração pode ser observado na Figura 2 abaixo.

Figura 2. Curvas de calibração para determinação da concentração do corante Vermelho Quimicryl GRL.

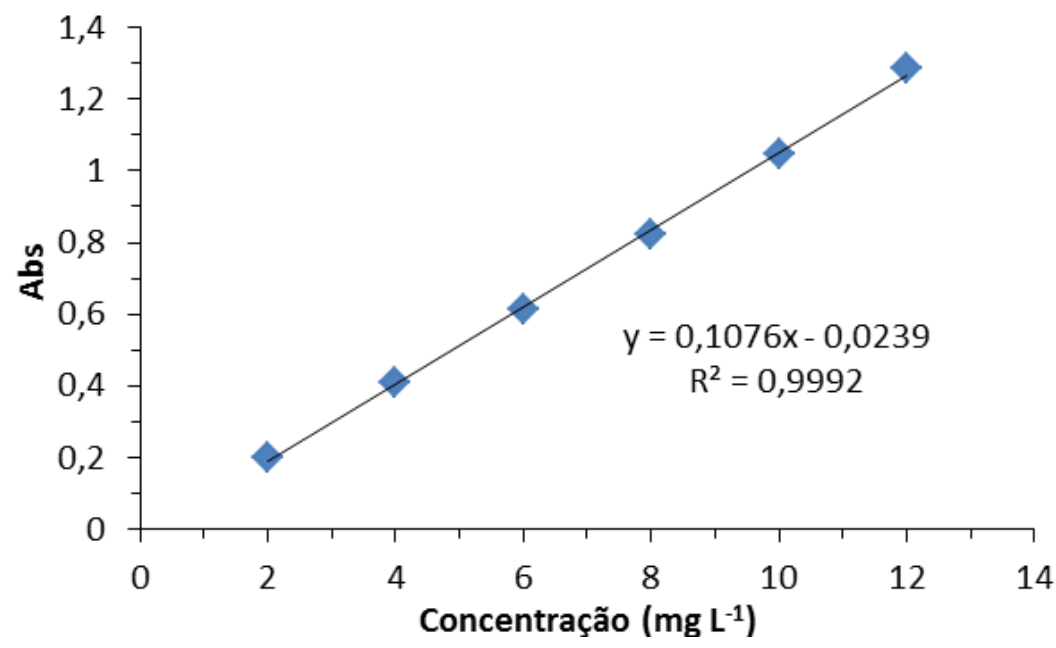

Fonte: Autores (2021).

Com a curva obtida foi realizada a equação da reta, para posteriormente utilizar-se nos cálculos de concentração, e também se obteve o coeficiente de correlação $\left(\mathrm{R}^{2}\right)$ de 0,9992 , esse valor é muito próximo de 1 , logo isso significa que existe uma boa correlação entre a variável na faixa de concentração estudada.

Após a curva de calibração ser obtida, iniciou-se o estudos de adsorção. O primeiro passo do trabalho foi a otimização da montagem da coluna, e otimização da massa a ser utilizada. Diversas massas foram testadas, com isso foi observado que quando utilizava-se a massas maiores a vazão da coluna era demasiadamente lenta, acarretando com isso a impossibilidade de sua aplicação. Foram testadas colunas com placa porosa, e colunas com algodão, com isso foi possível observar que quando utilizava-se a coluna com placa porosa, o processo de adsorção também se tornava lento, por isso foi definida o uso da coluna com algodão para realizar o empacotamento da coluna. Dessa forma as massas dos adsorventes e forma de preenchimento da coluna otimizados estão descritos no item 2.4 desse trabalho.

\subsection{Estudos de adsorção do corante Vermelho Quimicryl GRL}

$\mathrm{O}$ início dos estudos de adsorção para esse corante aconteceram com a montagem de curvas de saturação para ambas as biomassas, testando as duas in natura, ou tratadas com $\mathrm{NaOH}$ (Figuras 3 e 4). Foi escolhido o tratamento básico, ou seja com uso de $\mathrm{NaOH}$, pois o corante vermelho Quimicryl GRL tem caráter catiônico, dessa forma realizando esse tipo de tratamento, a superfície do adsorvente fica carregada negativamente, favorecendo a adsorção de espécies catiônicos. 
Figura 3. Curvas de saturação para a adsorção do corante Vermelho Quimicryl GRL em sementes de maracujá in natura e tratada com $\mathrm{NaOH}\left(\mathrm{Ci}=50 \mathrm{mg} \mathrm{L}^{-1}\right.$ e $\left.\mathrm{m}=0,8 \mathrm{~g}\right)$.

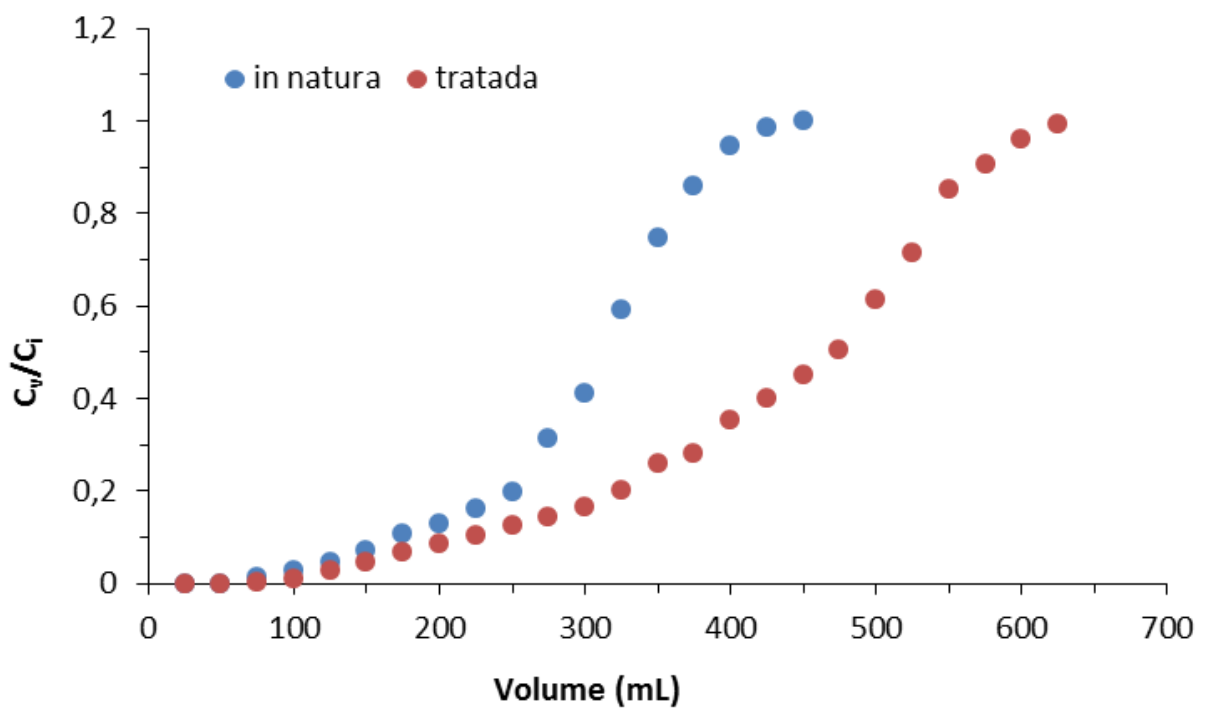

Fonte: Autores (2021).

Figura 4. Curvas de saturação para a adsorção do corante Vermelho Quimacryl GRL em cascas de maracujá in natura e tratada com $\mathrm{NaOH}\left(\mathrm{C}_{\mathrm{i}}=50 \mathrm{mg} \mathrm{L}^{-1}\right.$ e $\left.\mathrm{m}=0,6 \mathrm{~g}\right)$.

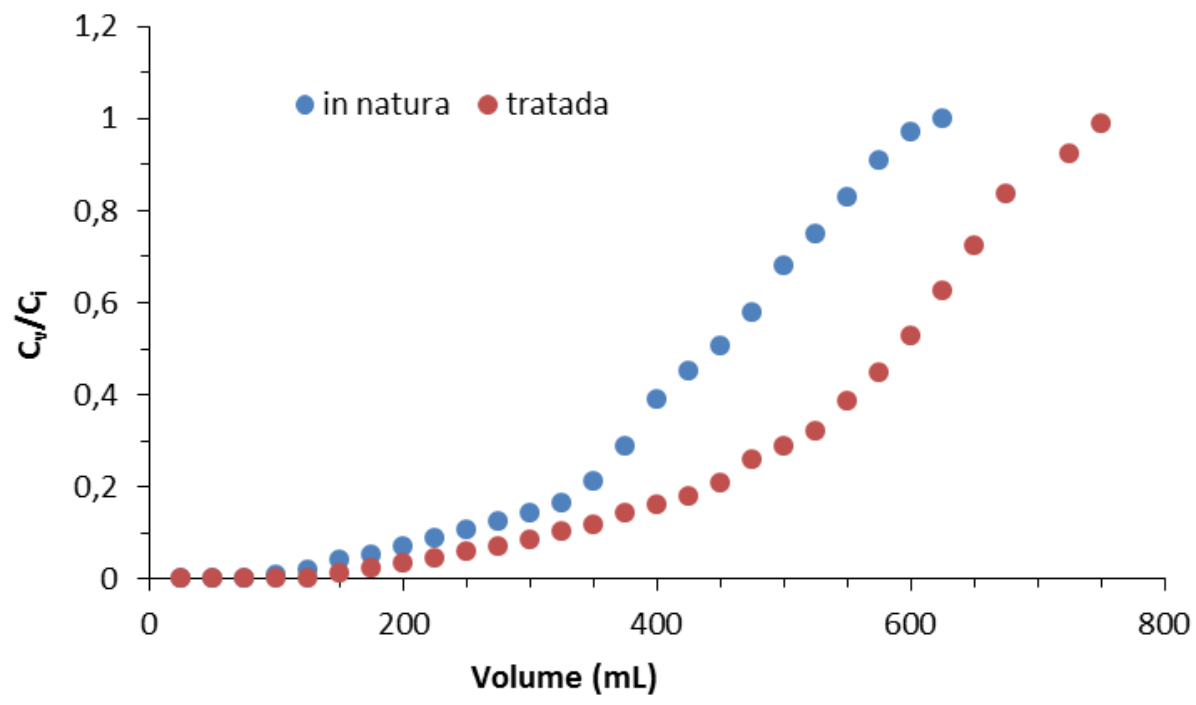

Fonte: Autores (2021).

Quando analisa-se a curva de saturação dois pontos devem ser considerados, o primeiro é o ponto no qual Cv/Ci deixa de ser diferente de zero, esse ponto é conhecido como ponto de ruptura, é o momento no qual começa a aparecer coloração na solução percolada. Outro ponto importante é o ponto de saturação, que é quando Cv/Ci é igual a 1 , nesse ponto temos que a concentração de saída igual a de entrada, nesse momento o adsorvente deve ser substituído.

Analisando a Figura 3 e 4 observou-se que as cascas e sementes de maracujá tratadas com $\mathrm{NaOH}$ foram mais eficientes que a in natura, pois apresentaram ponto de saturação superior. Para as sementes (Figura 3) o ponto de ruptura ocorreu em cerca de $100 \mathrm{~mL}$ para ambas as biomassas, tratada com $\mathrm{NaOH}$ e in natura, já o ponto de saturação aconteceu em $450 \mathrm{~mL}$ para a amostra in natura e $650 \mathrm{~mL}$ para a amostra tratada com NaOH. Já para as cascas houve o ponto de ruptura em 
$125 \mathrm{~mL}$ para a amostra in natura e em $150 \mathrm{~mL}$ para amostra tratada com NaOH, e os pontos de saturação são de 600 e $750 \mathrm{~mL}$, para as amostra in natura e tratada com $\mathrm{NaOH}$, respectivamente.

Com isso, comparando as Figuras 3 e 4 fica evidenciado que a casca foi mais eficiente do que a semente de maracujá para a adsorção do corante vermelho Quimicryl GRL. Fato interessante quando comparado com a conclusão de Castro, Alves, Saqueti, \& Montanher (2021), que utilizaram cascas e sementes de maracujá para o corante Nylosan Azul, e também observaram que as cascas tinham maior eficiência de adsorção.

Foi calculada a capacidade máxima de adsorção a partir da Equação 1, para o corante vermelho Quimicryl GRL nos diferentes tipos de resíduo de maracujá, os resultados obtidos encontram-se na Tabela 1.

Tabela 1. Capacidade máxima de adsorção do corante vermelho Quimacryl GRL em resíduo de Maracujá usando sistema de coluna de leito fixo.

\begin{tabular}{cc}
\hline Resíduo de Maracujá & q $\left(\mathbf{m g ~ g}^{-1}\right)$ \\
\hline Semente in natura & 18,6 \\
Semente tratada com NaOH & 26,9 \\
Casca in natura & 35,7 \\
Casca tratada com NaOH & 45,9 \\
\hline
\end{tabular}

Fonte: Autores (2021).

Analisando a Tabela 1 fica evidenciado que o tratamento químico aumentou a capacidade máxima de adsorção para o corante vermelho Quimicryl GRL, e novamente as cascas tiveram uma capacidade de adsorção maior que as sementes, portanto em escala industrial seria mais recomendado o uso das cascas de maracujá tratadas com $\mathrm{NaOH}$.

Montanher, de Farias, \& Dalpasquale (2019) também estudou a capacidade máxima de adsorção para esse corante em serragem de MDF, o valores encontrados foram de 19,9 para o adsorvente in natura e de 37,1 para o adsorvente tratado com $\mathrm{NaOH}$. Comparando seus resultados com o do presente trabalho, notou-se que a casca de maracujá tanto in natura quanto tratada com $\mathrm{NaOH}$ teve uma capacidade de adsorção maior, portanto teriam uma aplicação industrial satisfatória, pois uma mesma quantidade das cascas adsorveriam maiores quantidades de corantes do que a serragem de MDF.

O parâmetro da força iônica foi testado utilizando como eletrólito o $\mathrm{NaCl}$ em duas concentrações distintas, de 0,1 mol $\mathrm{L}^{-1}$ e $1 \mathrm{~mol} \mathrm{~L}^{-1}$, os resultados obtidos estão presentes nas Figuras 5 e 6. 
Figura 5. Efeito da Força iônica na adsorção do corante Vermelho Quimicryl GRL em sementes de maracujá in natura $(\mathrm{Ci}=$ $\left.50 \mathrm{mg} \mathrm{L}^{-1} \mathrm{e} \mathrm{m}=0,8 \mathrm{~g}\right)$.

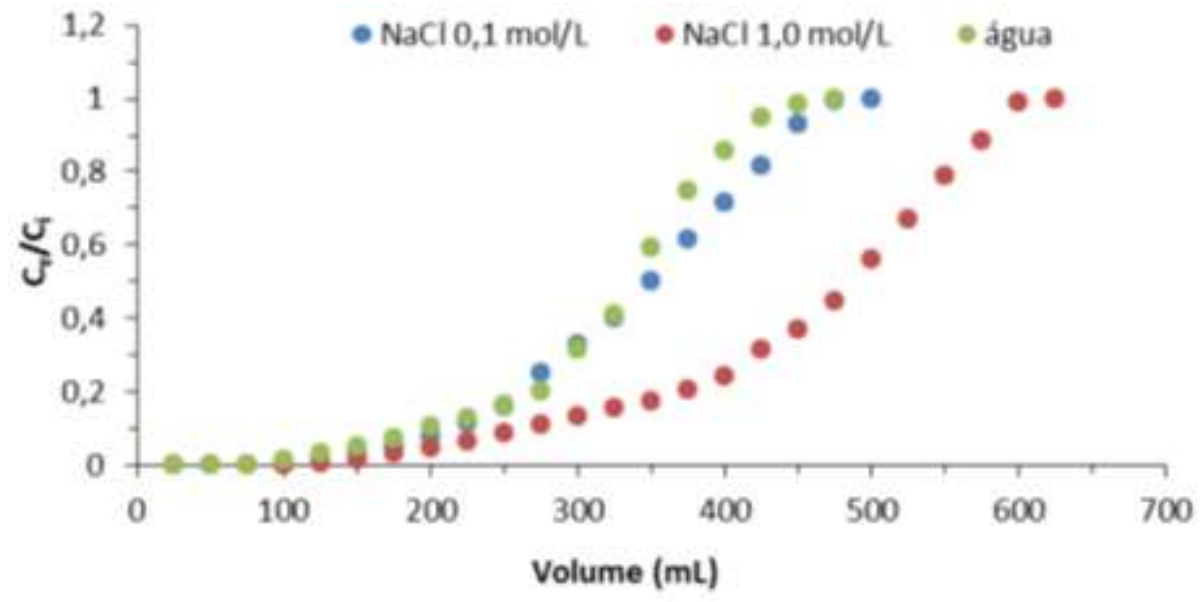

Fonte: Autores (2021).

Figura 6. Efeito da Força iônica na adsorção do corante Vermelho Quimicryl GRL em cascas de maracujá in natura $(\mathrm{Ci}=50$ $\mathrm{mg} \mathrm{L}^{-1}$ e $\left.\mathrm{m}=0,6 \mathrm{~g}\right)$.

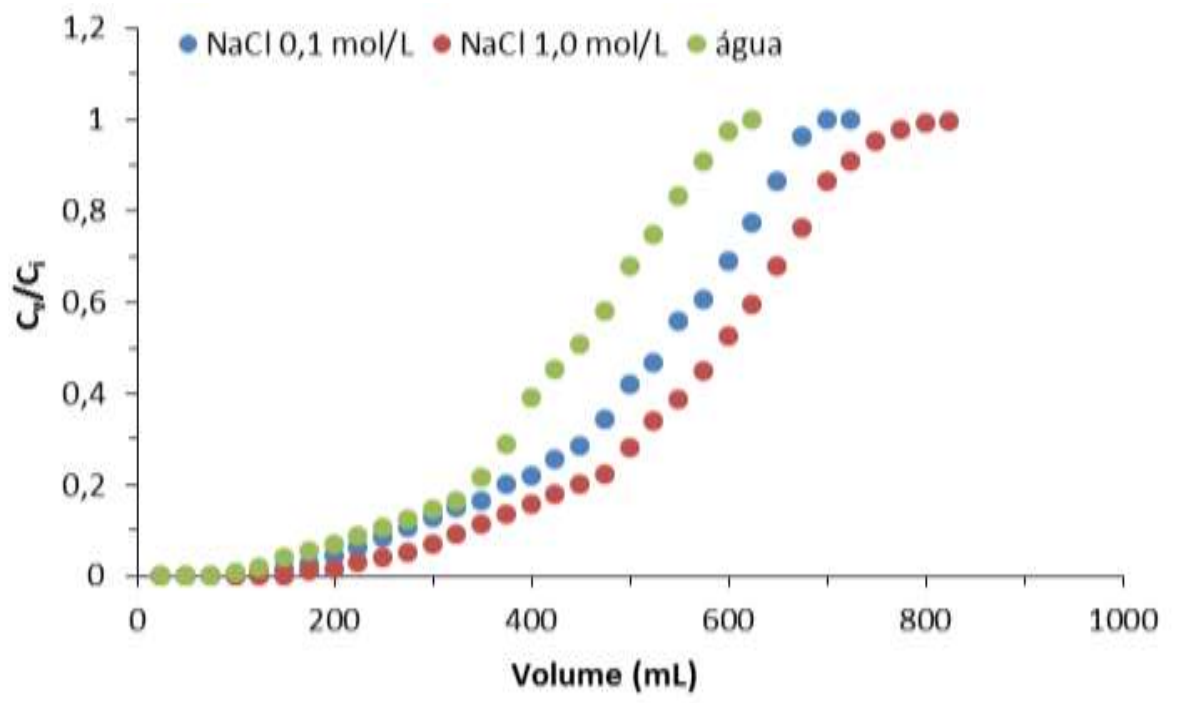

Fonte: Autores (2021).

Para a força iônica obteve-se que em ambos os casos o meio $\mathrm{NaCl}$ 1,0 mol L $\mathrm{m}^{-1}$ favoreceu o processo de adsorção, porém para as sementes isso fica mais evidente. Portanto, podemos concluir que para ambas as biomassas quanto maior a força iônica mais favorecida é a adsorção, isso tem uma importante aplicação industrial, nas indústrias que utilizam o cloreto de sódio, por exemplo, para aumentar a fixação do corante.

O corante vermelho quimacryl GRL faz parte do grupo de corantes básicos catiônicos devido a presença de grupos amino protonados. $\mathrm{O}$ pH da solução aquosa $50 \mathrm{mg} \mathrm{L}^{-1}$ do corante vermelho é 5,7 devido a hidrólise desse grupo:

$$
\mathrm{R}-\mathrm{NH}_{3}{ }^{+}{ }_{\text {aq }}+\mathrm{H}_{2} \mathrm{O}_{(\mathrm{l})} \rightleftarrows \mathrm{R}-\mathrm{NH}_{2(\mathrm{aq})}+\mathrm{H}_{3} \mathrm{O}^{+}
$$

As Figuras 7 e 8 apresentam o efeito do pH na adsorção do corante vermelho em resíduos de maracujá. 
Figura 7. Efeito do $\mathrm{pH}$ na adsorção do corante Vermelho Quimicryl GRL em sementes de maracujá in natura $\left(\mathrm{C}_{\mathrm{i}}=50 \mathrm{mg} \mathrm{L}^{-1} \mathrm{e}\right.$ $\mathrm{m}=0,8 \mathrm{~g})$.

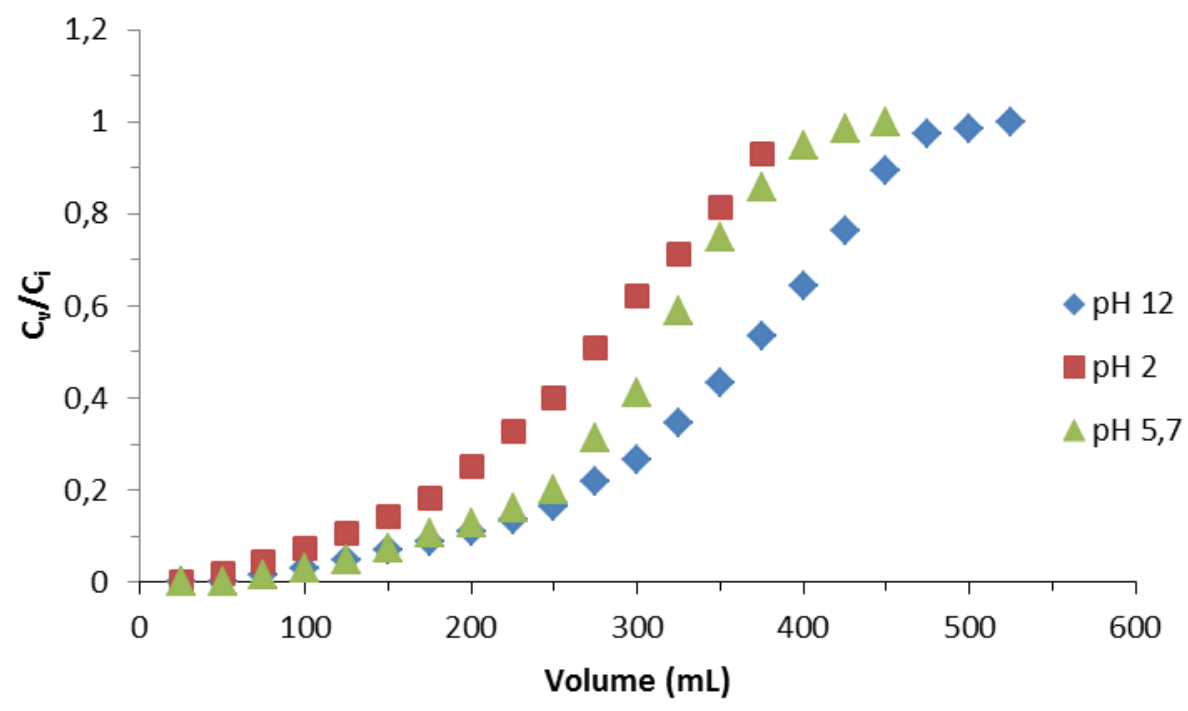

Fonte: Autores (2021).

Figura 8. Efeito do pH na adsorção do corante Vermelho Quimicryl GRL em cascas de maracujá in natura $\left(\mathrm{C}_{\mathrm{i}}=50 \mathrm{mg} \mathrm{L}^{-1} \mathrm{e}\right.$ $\mathrm{m}=0,6 \mathrm{~g})$.

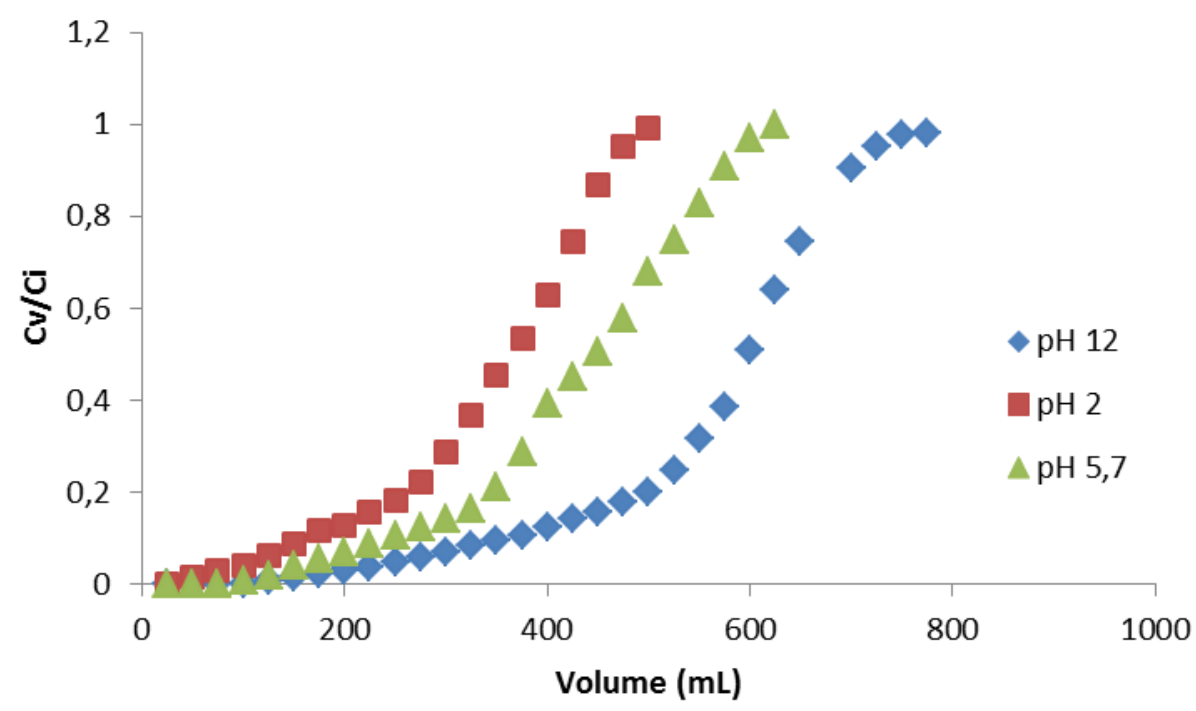

Fonte: Autores (2021).

Analisando as Figuras 7 e 8, pode-se considerar que em pH ácido, o processo de adsorção do corante vermelho Quimicryl GRL foi afetado negativamente, já em pH básico o processo de adsorção foi favorecido, isso ocorre, pois, o corante é catiônico e em pH básico a superfície do adsorvente fica negativa.

Após os testes realizados, foi realizado o processo de dessorção para o corante vermelho Quimicryl GRL (Figuras 9 e $10)$. 
Figura 9. Curva de dessorção do corante Vermelho Quimacryl GRL retido em sementes de maracujá in natura e tratada com $\mathrm{NaOH}$

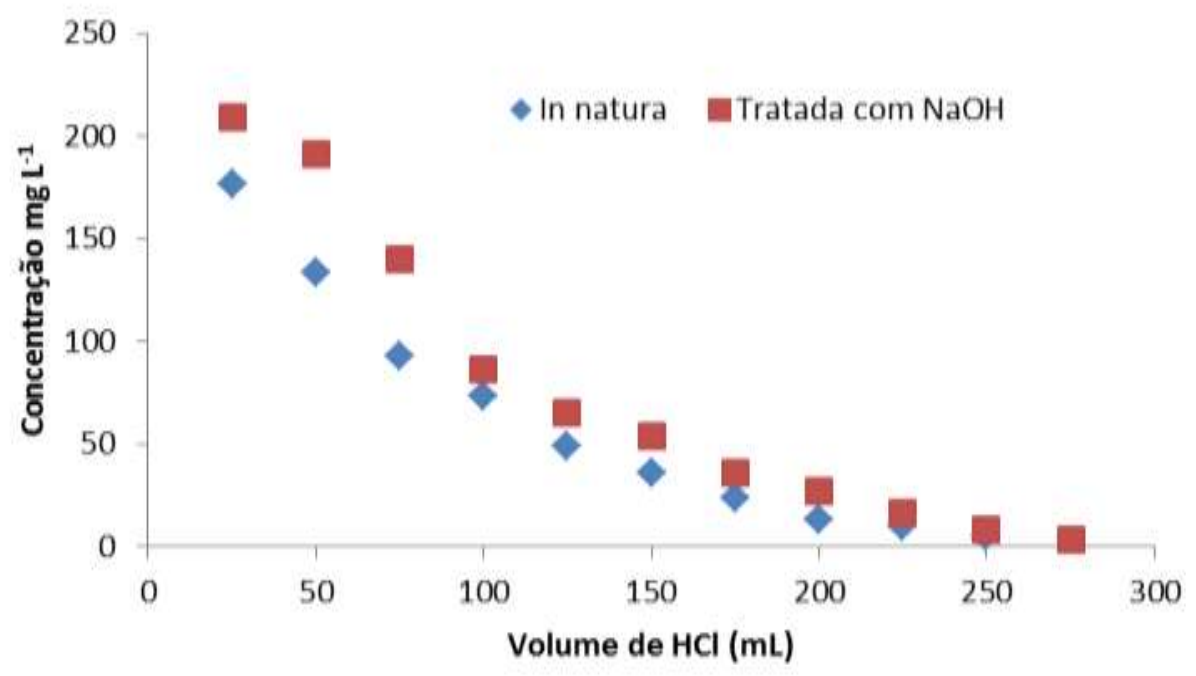

Fonte: Autores (2021).

Figura 10. Curva de dessorção do corante Vermelho Quimacryl GRL retido em cascas de maracujá in natura e tratada com $\mathrm{NaOH}$.

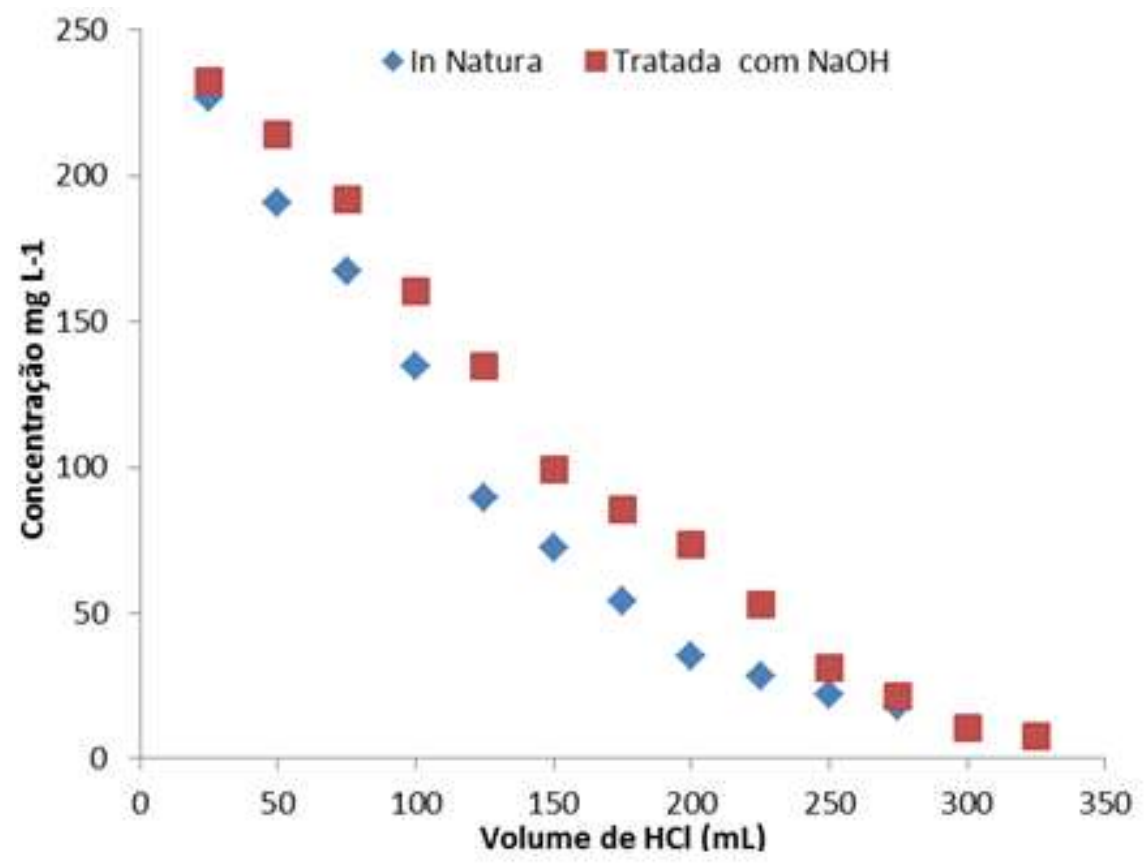

Fonte: Autores (2021).

Em ambos os resíduos de maracujá tanto in natura quanto tratados com $\mathrm{NaOH}$ o processo de dessorção foi possível usando ácido clorídrico $(\mathrm{HCl})$ como trocador cationico com o corante vermelho Quimicryl GRL. Praticamente todo corante pôde ser recuperado com $300 \mathrm{~mL}$ de $\mathrm{HCl}$. 
Após o processo de dessorção o corante poderia ser recuperado e utilizado novamente, mostrando dessa forma como o processo de adsorção tem inúmeras aplicações industriais. Além disso, foi perceptível que a melhor biomassa foram as cascas, e que o fator força iônica e pH influenciam diretamente no processo de adsorção.

\section{Conclusão}

A partir dos estudos de adsorção analisados foi possível concluir que o corante vermelho Quimicryl GRL em ambas as biomassas, cascas e sementes, o processo se tornou viável. Nos ensaios testando o efeito do pH foi possível observar que em pH maiores, ou seja, básicos, a eficiência de adsorção aumenta. O tratamento químico aumentou a capacidade de adsorção para as sementes, mas em ambos os casos o aumento foi significativo, acima dos $25 \%$. Além disso, a força iônica influenciou diretamente no processo de adsorção.

O processo de dessorção foi possível tanto nos resíduos de maracujá in natura e tratados com NaOH e sendo possível o corante e a biomassa serem reutilizados novamente. O melhor resultado de capacidade máxima de adsorção para o corante vermelho Quimicryl GRL foram as cascas de maracujá tratadas com $\mathrm{NaOH}$, apresentando resultado de 45,9 mg $\mathrm{g}^{-1}$. Logo ambas as biomassas podem ser utilizadas em escala industrial como adsorventes alternativos de corantes. O uso e estudo de biomassas como adsorventes alternativos se faz cada vez mais necessário, para deixar o processo de adsorção mais barato e eficaz, desse modo trabalhos futuros são sugeridos com outras matrizes.

\section{Agradecimentos}

Os autores agradecem a Universidade Tecnológica Federal do Paraná - Campus Apucarana, Conselho Nacional de Desenvolvimento Científico e Tecnológico $(\mathrm{CNPq})$ e Coordenação de Aperfeiçoamento de Pessoal de Nível Superior (CAPES) pelo auxílio financeiro.

\section{Referências}

Abd, A. A., Naji, S. Z., Hashim, A. S., \& Othman, M. R. (2020). Carbon dioxide removal through physical adsorption using carbonaceous and noncarbonaceous adsorbents: a review. Journal of Environmental Chemical Engineering, 8, 104142.

Acharya, J., Kumar, U., \& Rafi, P. M. (2018). Removal of heavy metal ions from wastewater by chemically modified agricultural waste material as potential adsorbent-a review. International Journal of Current Engineering and Technology, 8, 526-530.

Aleem, M., Cao, J., Li, C., Rashid, H., Wu, Y., Nawaz, M. I.,... \& Akram, M. W. (2020). Coagulation-and adsorption-based environmental impact assessment and textile effluent treatment. Water, Air, \& Soil Pollution, 231, 1-8.

Assila, O., Tanji, K., Zouheir, M., Arrahli, A., Nahali, L., Zerrouq, F., \& Kherbeche, A. (2020). Adsorption studies on the removal of textile effluent over two natural eco-friendly adsorbents. Journal of Chemistry, 2020, 1-13.

Bharathi, K. S., \& Ramesh, S. T. (2013). Removal of dyes using agricultural waste as low-cost adsorbents: a review. Applied Water Science, 3, 773-790.

Bouatay, F., Dridi-Dhaouadi, S., Drira, N., \& Farouk Mhenni, M. (2016). Application of modified clays as an adsorbent for the removal of Basic Red 46 and Reactive Yellow 181 from aqueous solution. Desalination and Water Treatment, 57, 13561-13572.

Castro, M. C., Alves, E. S., Saqueti, B. H. F., \& Montanher, S. F. (2021). Estudo de adsorção do corante Nylosan azul N-BLN têxtil em resíduos de semente de maracujá. Research, Society and Development, 10, e573101321594.

Dallago, R. M., Smaniotto, A., \& Oliveira, L. C. A. D. (2005). Resíduos sólidos de curtumes como adsorventes para a remoção de corantes em meio aquoso. Química Nova, 28, 433-437.

Dutta, S., Gupta, B., Srivastava, S. K., \& Gupta, A. K. (2021). Recent advances on the removal of dyes from wastewater using various adsorbents: a critical review. Materials Advances, 2 , 4497-4531.

Gerola, G. P., Boas, N. V., Caetano, J., Tarley, C. R. T., Gonçalves, A. C., \& Dragunski, D. C. (2013). Utilization of passion fruit skin by-product as lead (II) ion biosorbent. Water, Air, \& Soil Pollution, 224, 1-11.

Guaratini, C. C., \& Zanoni, M. V. B. (2000). Corantes têxteis. Química nova, 23, 71-78. 
Research, Society and Development, v. 10, n. 14, e266101422059, 2021 (CC BY 4.0) | ISSN 2525-3409 | DOI: http://dx.doi.org/10.33448/rsd-v10i14.22059

Kausar, A., Iqbal, M., Javed, A., Aftab, K., Bhatti, H. N., \& Nouren, S. (2018). Dyes adsorption using clay and modified clay: a review. Journal of Molecular Liquids, 256, 395-407.

Khuwijitjaru, P., \& Klinchongkon, K. (2020). Passion fruit. In Valorization of Fruit Processing By-products. Academic Press. 183-201

Milonjić, S. K. (2007). A consideration of the correct calculation of thermodynamic parameters of adsorption. Journal of the Serbian chemical society, 72, $1363-1367$.

Montanher, S. F., de Farias, L. B. N., \& Dalpasquale, M. (2019). Adsorção de corantes têxteis em serragem de MDF (Medium-Density Fiberboard). Brazilian Journal of Development, 5, 14776-14789.

Ncibi, M. C., Mahjoub, B., \& Seffen, M. (2007). Adsorptive removal of textile reactive dye using Posidonia oceanica (L.) fibrous biomass. International Journal of Environmental Science \& Technology, 4, 433-440.

Peker, S., Yapar, S., \& Beşün, N. (1995). Adsorption behavior of a cationic surfactant on montmorillonite. Colloids and Surfaces A: Physicochemical and Engineering Aspects, 104, 249-257.

Pinto, T. F., Bezerra, C. W., Silva, D. S., SILVA, E. C., Vieira, A. P., Airoldi, C., ... \& Santana, S. A. (2016). Derivado da serragem para aplicação ambiental: química, funcionalização e remoção de corante têxtil em solução aquosa. Anais da Academia Brasileira de Ciências, 88 , $1212-1220$.

Rahmani, M., \& Sasani, M. (2016). Evaluation of 3A zeolite as an adsorbent for the decolorization of rhodamine B dye in contaminated waters. Applied Chemistry, 11, 83-90.

Ruthven, D. M. (1984). Principles of adsorption and adsorption processes. John Wiley \& Sons.

Salleh, M. A. M., Mahmoud, D. K., Karim, W. A. W. A., \& Idris, A. (2011). Cationic and anionic dye adsorption by agricultural solid wastes: a comprehensive review. Desalination, 280, 1-13.

Samico, G. F. (2010). Caracterização física e química de sementes de maracujá (Passiflora edulis flavicarpa, Deg) e seu aproveitamento integral: óleo e torta. [Dissertação (Mestrado) Universidade Federal Rural do Rio de Janeiro, Seropédica, Rio de Janeiro. 65]. 